\title{
BALANÇO HÍDRICO EM NEOSSOLO REGOLÍTICO CULTIVADO COM BRAQUIÁRIA (Brachiaria decumbens Stapf) ${ }^{(1)}$
}

\author{
Renan Almeida Brito da Silva ${ }^{(2)}$, José Romualdo de Sousa Lima ${ }^{(3)}$, Antônio Celso Dantas \\ Antonino $^{(4)}$, Patrícia Sousa de Sales Gondim( ${ }^{(2)}$, Eduardo Soares de Souza ${ }^{(5)}$ \& Genival \\ Barros Júnior ${ }^{(5)}$
}

\begin{abstract}
RESUMO
Um dos principais fatores de produção para as culturas é a disponibilidade de água no solo, de forma que a quantificação das entradas e saídas dessa água, por meio do método do balanço hídrico, pode ser um instrumento valioso para melhorar o manejo dado a ela. Desse modo, este trabalho teve como objetivo analisar os componentes do balanço hídrico (variação do armazenamento de água no solo, drenagem, ascensão capilar e evapotranspiração) e o perfil do sistema radicular em Brachiaria decumbens, em nove meses do ano de 2011 (março a novembro). Também foi avaliada a razão entre evapotranspiração (ET) e evapotranspiração de referência (ETo). Esta pesquisa foi realizada na fazenda Riacho do Papagaio, em São João, na mesorregião do Agreste do Estado de Pernambuco, onde foram instalados sensores automatizados para medição da umidade volumétrica do solo nas profundidades de 0,$10 ; 0,20 ; 0,30 ;$ e $0,40 \mathrm{~m}$. A precipitação pluvial foi monitorada por meio de um pluviógrafo automatizado instalado numa torre no centro da área. Para a determinação da drenagem e da ascensão capilar, foram realizados ensaios de infiltração para obtenção da condutividade hidráulica do solo, além da determinação da curva de retenção, em laboratório. A ET foi obtida como termo residual da equação do balanço hídrico e a ETo, pelo método de Penman-Monteith. O volume de controle utilizado para o balanço hídrico teve como limite superior a
\end{abstract}

(1) Parte da Dissertação de Mestrado do primeiro Autor apresentada ao Programa de Pós-Graduação em Produção Agrícola, Unidade Acadêmica de Garanhuns - Universidade Federal Rural de Pernambuco - UAG/UFRPE. Projeto financiado pelo CNPq (processo 475094/2009-3) e pela FACEPE (Edital 02/2009 e Edital 12/2010 PRONEM/FACEPE/CNPq). Recebido para publicação em 9 de novembro de 2012 e aprovado em 25 de outubro de 2013.

(2) Mestre do Programa de Pós-Graduação em Produção Agrícola, UAG/UFRPE. Av. Bom Pastor, s/n, Boa Vista. CEP 55292-270 Garanhuns (PE). E-mail: silva_r.a.b@agro.adm.br, patricia.s.gondim@hotmail.com

(3) Professor Adjunto, UAG/UFRPE. E-mail: romualdo@uag.ufrpe.br

(4) Professor Associado, Departamento de Energia Nuclear, Universidade Federal de Pernambuco. Av. Prof. Luiz Freire, 1000. CEP 50740-540 Recife (PE). Pesquisador do CNPq. E-mail: acda@ufpe.br

(5) Professor Adjunto, Unidade Acadêmica de Serra Talhada/UFRPE. Fazenda Saco, s/n. Caixa Postal 063. CEP 56900-000 Serra Talhada (PE). E-mail: eduardosouza@uast.ufrpe.br, barrosjnior@yahoo.com.br 
superfície do solo e como limite inferior a profundidade de $0,30 \mathrm{~m}$. Também foi analisado o perfil do sistema radicular da braquiária, mensalmente. Observou-se que os períodos com elevadas pluviosidades resultaram num maior armazenamento de água no solo, em maiores valores de drenagem e de evapotranspiração. $O$ fluxo de água no limite inferior $(\mathrm{z}=0,30 \mathrm{~m})$ do solo ocorreu somente no sentido descendente, sendo perdidos $103,14 \mathrm{~mm}$ de água por drenagem, o que representa $\mathbf{2 4 , 1 2} \%$ de toda a água fornecida à cultura. A evapotranspiração total da Brachiaria decumbens Stapf foi de $324,96 \mathrm{~mm}$, com valor médio de $1,2 \mathrm{~mm} \mathrm{~d}^{-1}$. A pastagem sofreu estresse hídrico, em quase todo período experimental, tendo em vista os valores da relação ET/ETo serem inferiores a 1. Os baixos valores da razão ET/ETo indicaram a necessidade de se realizar irrigação para se diminuir o déficit hídrico. No entanto, em razão dos elevados valores de drenagem, recomendam-se práticas de manejo que aumentem a retenção de água pelo solo.

Termos de indexação: umidade do solo, condutividade hidráulica, curva de retenção, drenagem.

\section{SUMMARY: WATER BALANCE IN REGOSOLS CULTIVATED WITH SIGNAL GRASS (Brachiaria decumbens Stapf)}

One of the main crop production factors is soil water availability; therefore, determination of soil water inputs and outputs by the water balance method can be a valuable tool for improving crop management. The aim of this study was to assess soil water balance components in the field (soil water storage variations, drainage, capillary rise and evapotranspiration) and the root system profile of Brachiaria decumbens for nine months in 2011 (March to November). The ratio between evapotranspiration (ET) and reference evapotranspiration (ETo) was evaluated as well. The study was carried out in an experimental area at the "Riacho do Papagaio" farm, municipality of São João, state of Pernambuco, Brazil. TDR probes were set up at depths of 0.10, 0.20, 0.30 and $0.40 \mathrm{~m}$ to measure soil water content. Rainfall was monitored with a rain gauge installed on a tower in the center of the area. For the determination of drainage and capillary rise, infiltration tests were performed in the field to obtain the saturated hydraulic conductivity. The soil water retention curve was determined in the laboratory. ET was obtained as a residual term of the water balance equation and ETo was obtained by the Penman-Monteith method. The upper limit of the control volume used for water balance was the soil surface, and the lower limit was a plane parallel to the soil surface at a depth of $0.30 \mathrm{~m}$. Each month, the root system profile was analyzed. It was observed that substantial soil water storage, drainage and ET values occurred in the high rainfall periods. Water flux through the plane of the lower limit $(z=0.30 \mathrm{~m})$ occurred only downwards, with a loss of $103.14 \mathrm{~mm}$ by drainage, which is $24.12 \%$ of the water supplied to the crop. The total value and average value for actual evapotranspiration of Brachiaria decumbens were $324.96 \mathrm{~mm}$ and $1.2 \mathrm{~mm} \mathrm{~d}^{-1}$ respectively. The grassland must have undergone water stress throughout the entire experimental period since the values of the ET/ETo ratio are much lower than one. The low value of the ET/ETo ratio indicates the need for irrigation to reduce water deficit. However, due to high drainage values, management practices for increasing soil water retention are recommended.

Index terms: soil water content, hydraulic conductivity, retention curve, internal drainage.

\section{INTRODUÇÃO}

As pastagens recobrem cerca de dois terços de toda a área agricultável do globo terrestre. No Brasil, ocupam cerca de 172 milhões de ha (IBGE, 2006), assumindo posição de destaque no cenário agrícola brasileiro. No Estado de Pernambuco a área ocupada com pastagens é de 2.506.730 ha; já a área ocupada por pastagens na mesorregião do Agreste Pernambucano é de 1.066.776 ha, com 276.613 ha situados na microrregião de Garanhuns (IBGE, 2006).
Quando relacionada à área de pastagem cultivada, estima-se valor maior que 101 milhões de ha cultivados em todo o país, e que $85 \%$ dessa área sejam ocupadas por brachiária (Barbosa, 2006).

Apesar de sua representatividade no território brasileiro, não se obtém uma excelência de produção dessas pastagens. No tocante às pastagens existentes no agreste meridional de Pernambuco, essas evidenciam níveis de rendimento de matéria seca muito baixo (500 kg ha-1), refletindo elevado estado de degradação resultante do manejo inadequado do solo 
(Ydoyaga et al., 2006). Essa degradação faz com que ocorra redução na produtividade, perda de matéria orgânica do solo ou maior emissão de $\mathrm{CO}_{2}$ para atmosfera, com redução no sequestro do carbono na pastagem (Nicoloso et al., 2008).

De acordo com Euclides et al. (2007), a produção de forragem é dependente da temperatura e da radiação e é limitada pela disponibilidade de nutrientes e água. Além disso, as incertezas climáticas, principalmente relacionadas com a precipitação pluvial, também regulam a oscilação da produção das pastagens.

No entanto, apenas os dados de precipitação pluvial não são suficientes para se previr a quantidade de água disponível no solo para as culturas, uma vez que esses informam tão somente a entrada de água no solo. Faz-se necessário conhecer também as perdas de água do solo, sejam as relacionadas à evapotranspiração sejam aquelas relacionadas com a drenagem e com o escoamento superficial, evidenciando a necessidade de realizar o balanço hídrico no solo.

O conhecimento do modo como as plantas utilizam a água no solo e de como respondem aos níveis de armazenagem a partir do balanço hídrico, pode ser uma saída viável para o estabelecimento de estratégias eficazes de manejo, visando ao melhor uso possível das reservas de água no solo pelas culturas. O movimento cíclico da água na lavoura começa com a penetração no solo por meio da infiltração, continua com o armazenamento temporário na zona do sistema radicular e termina com a remoção do solo por meio da drenagem, evaporação e absorção pelas raízes (Hillel, 1998).

O método do balanço hídrico vem sendo usado por muitos cientistas para estimar o consumo hídrico e, ou, a eficiência no uso de água para várias culturas (Cruz et al., 2005; Lima et al., 2006a; Prevedello et al., 2007; Brito et al., 2009; Ward et al., 2012); no entanto, não se tem conhecimento do uso desse método para se estimar o consumo hídrico do capim-braquiária na Região Nordeste. Desse modo, o objetivo deste trabalho foi analisar os componentes do balanço hídrico (variação do armazenamento de água no solo, drenagem, ascensão capilar e evapotranspiração), além do perfil do sistema radicular, em uma área de pastagem (Brachiaria decumbens Stapf.) no Agreste Meridional de Pernambuco.

\section{MATERIAL E MÉTODOS}

As medidas para a realização do balanço hídrico foram efetuadas em uma área de pastagem de Brachiaria decumbens Stapf, cultivada na fazenda Riacho do Papagaio, no município de São João, na mesorregião do Agreste Meridional do Estado de Pernambuco ( $8^{\circ} 52^{\prime} 30^{\prime \prime}$ S e $36^{\circ} 22^{\prime} 00^{\prime \prime} \mathrm{O}$, com altitude de 705 m). O clima predominante na região é o As', que equivale a um clima quente e úmido, conforme classificação de Köppen (Andrade, 2007). De acordo com dados da Agência Pernambucana de Águas e Clima (APAC, 2013), a precipitação pluvial anual média é de $782 \mathrm{~mm}$, sendo o quadrimestre mais chuvoso constituído dos meses de maio a agosto (Figura 1). O solo da área é classificado como Neossolo Regolítico eutrófico típico (Santos et al., 2012).

A área, onde foram realizadas as medições, tem 22 ha e era originalmente formada por uma vegetação típica do Agreste, a qual foi removida por volta de 1950, quando se iniciou a atividade agrícola desse local. No decorrer dos primeiros 30 anos, prevaleceram culturas de ciclo anual (milho, algodão e feijão), cujo cultivo era realizado via manejo convencional de preparo do solo com revolvimento, sem rotação de culturas e adubação para a reposição dos nutrientes ao solo. Posteriormente, por volta do ano 2000, converteu-se a área em pastagens de Brachiaria decumbens Stapf (Ydoyaga et al., 2006). A pastagem atualmente está sob pastejo de bovinos mestiço, com uma taxa de lotação de $1 \mathrm{UA} \mathrm{ha}^{-1}$.

Foram coletadas amostras deformadas e indeformadas de solo nas profundidades de 0,0-0,20; 0,20-0,40; e 0,40-0,60 m. Essas amostras foram retiradas de três perfis e de cada camada foram coletadas três amostras.

Nas amostras deformadas, foram determinadas a composição granulométrica do solo, pelo método do densímetro, e a densidade de partículas, pelo método do picnômetro (Embrapa, 1997).

Nas amostras indeformadas, determinou-se a densidade do solo, utilizando-se o amostrador de Uhland, com anéis de PVC com 0,05 $\mathrm{m}$ de altura e 0,05 m de diâmetro, conforme Embrapa (1997). A porosidade total foi obtida pela relação entre densidade do solo e densidade de partículas.

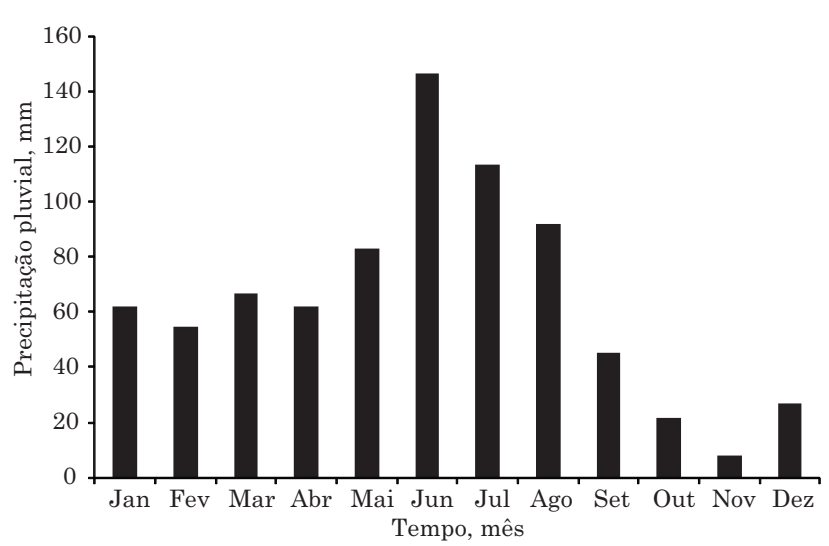

Figura 1. Média mensal da precipitação pluvial (de 1999 a 2011) do município de São João, PE. Dados da Agência Pernambucana de Águas e Clima (APAC, 2013). 
O estudo dos componentes do balanço hídrico foi realizado no período de $1^{\circ}$ de março a 30 de novembro de 2011, totalizando 275 dias, o qual foi dividido em 18 subperíodos, sendo 13 com 15 dias e cinco com 16 dias.

De acordo com Prevedello et al. (2007), o balanço hídrico num ambiente vegetado é a contabilização das entradas e saídas de água num dado volume de solo, durante certo período de tempo. O volume de solo considerado depende da vegetação em estudo, pois ele deve englobar seu sistema radicular. Assim, considerase como limite superior desse volume a superfície do solo e como limite inferior a profundidade do sistema radicular da vegetação de interesse. No caso desta pesquisa, considerou-se a profundidade de $0,30 \mathrm{~m}$ como limite inferior.

O balanço hídrico em determinado volume de solo, num certo período de tempo (Libardi, 2000), é descrito pela equação 1:

$$
\Delta \mathrm{A}=\mathrm{P}+\mathrm{I} \pm \mathrm{Q}-\mathrm{R}-\mathrm{ET}
$$

sendo $\Delta \mathrm{A}$ a variação de armazenamento de água no solo; P a precipitação; I a irrigação; Q o fluxo total de drenagem (-Q) ou ascensão capilar $(+Q)$; R o escoamento superficial; e ET a evapotranspiração, todos expressos em $\mathrm{mm}$. Conhecendo-se todos os componentes do balanço hídrico, a ET é obtida como termo residual da equação 1 .

Nas condições experimentais de campo, o fator irrigação (I) foi nulo, pois o trabalho se realizou em condições de sequeiro. Considerou-se que não ocorreu escoamento superficial de água, em razão de o solo ter declividade inferior a $5 \%$ e elevada drenagem (Lima et al., 2006a; Brito et al., 2009). A precipitação pluvial foi monitorada por meio de um pluviógrafo automatizado (modelo TE 525WS-L, Texas Electronics, USA), instalado numa torre no centro da área. A precisão do pluviógrafo é de $1 \%$ e as leituras foram feitas a cada minuto, com o valor total de cada 30 min armazenados num sistema de aquisição de dados (modelo CR1000, Campbell Scientific Inc., USA).

Foi utilizada a regra do trapézio (Libardi, 2000) para calcular o armazenamento acumulado de água no solo, considerando-se que as medidas foram realizadas em intervalos igualmente espaçados, desde a superfície $(\mathrm{z}=0)$ até a profundidade de interesse $(\mathrm{z}$ $=\mathrm{L}=0,30 \mathrm{~m}$ ). A variação no armazenamento de água no perfil de solo $(\Delta \mathrm{A})$ foi determinada pela diferença dos valores do armazenamento de água do perfil nos tempos inicial e final de cada período considerado, sendo expressa pela seguinte equação:

$$
\Delta \mathrm{A}=\left[\theta_{(\mathrm{f})}-\theta_{(\mathrm{i})}\right] \mathrm{l}=\mathrm{A}_{\mathrm{f}}-\mathrm{A}_{\mathrm{i}}
$$

sendo $\mathrm{L}$ a profundidade e $\mathrm{A}_{\mathrm{f}}$ e $\mathrm{A}_{\mathrm{i}}$ os armazenamentos acumulados de água final e inicial, respectivamente.

Para as determinações da umidade volumétrica $\left(\theta, \mathrm{m}^{3} \mathrm{~m}^{-3}\right)$, foram instalados sensores automatizados tipo TDR (modelo CS 616 da Campbell Scientific Inc., USA) nas profundidades de 0,$10 ; 0,20 ; 0,30$; e $0,40 \mathrm{~m}$.
As leituras foram realizadas a cada minuto com o valor de cada 30 min armazenados num sistema de aquisição de dados (modelo CR1000, Campbell Scientific Inc., USA). Foi usada a equação de calibração sugerida pelo fabricante (Equação 3), pois Lima et al. (2006b), ao compararem a umidade volumétrica medida com esses sensores, com medidas gravimétrica e de sonda de nêutrons, não encontraram diferença estatística entre os valores de umidade do solo.

$$
\theta=-0,0663-0,0063^{*} \tau+0,0007^{*} \tau^{2}
$$

sendo $\tau$ o período de medição em microssegundos.

O fluxo total de água (Q), ou seja, as perdas por drenagem (-Q) ou os ganhos por ascensão capilar (+Q), de água da zona radicular por meio do limite inferior do volume de solo estudado $(\mathrm{z}=0,30 \mathrm{~m})$, respectivamente, foram determinados a partir da equação:

$$
\mathrm{Q}=\int_{0}^{\mathrm{t}} \mathrm{qdt}=\mathrm{q} \int_{0}^{\mathrm{t}} \mathrm{dt}=\mathrm{q}(\mathrm{t}-0)=\mathrm{q} \Delta \mathrm{t}
$$

sendo $\mathrm{q}\left(\mathrm{mm} \mathrm{d}^{-1}\right)$ a densidade de fluxo de água no limite inferior do volume de solo delimitado pela zona radicular e dt o intervalo de tempo de estudo do balanço hídrico. As densidades de fluxo q foram estimadas com base na equação de Darcy-Buckingham:

$$
q=-K(\theta) \frac{\Delta \psi_{t}}{\Delta z}
$$

sendo $\mathrm{K}(\theta)\left(\mathrm{mm} \mathrm{d}^{-1}\right)$ a condutividade hidráulica não saturada e $\Delta \psi_{t} / \Delta \mathrm{z}$ o gradiente de potencial total em $\mathrm{z}=0,30 \mathrm{~m}$, obtido pela equação abaixo:

$$
\frac{\Delta \psi_{\mathrm{t}}}{\Delta \mathrm{z}}=\frac{\psi_{\mathrm{t} 0,20 \mathrm{~m}}-\psi_{\mathrm{t} 0,40 \mathrm{~m}}}{\Delta \mathrm{z}}
$$

sendo $y_{\mathrm{t}}$ o potencial total da água no solo $\left(\psi_{\mathrm{t}}=\psi_{\mathrm{m}}+\psi_{\mathrm{g}}\right)$ e $\Delta$ z igual a $0,20 \mathrm{~m}$. O potencial gravitacional $\psi_{\mathrm{g}}(\mathrm{cm}$ de água) foi definido pela posição no solo, ou seja, igual à profundidade $\mathrm{z}$; e o potencial matricial $\psi_{\mathrm{m}}(\mathrm{cm}$ de água), por meio da equação de van Genuchten (1980) e dos dados da curva de retenção e de umidade do solo.

A curva de retenção foi obtida em laboratório usando-se extrator de Richards, de acordo com Embrapa (1997). Os dados das curvas de retenção da água no solo foram ajustados pela equação proposta por van Genuchten (1980):

$$
\theta\left(\psi_{\mathrm{m}}\right)=\theta_{\mathrm{r}}+\left(\theta_{\mathrm{s}}-\theta_{\mathrm{r}}\right)\left[1+\left|\alpha \psi_{\mathrm{m}}\right|^{\mathrm{n}}\right]^{-\mathrm{m}}
$$

com a hipótese de Burdine (1953):

$$
\mathrm{m}=1-\frac{2}{\mathrm{n}}
$$

sendo $\theta_{\mathrm{s}}$ o conteúdo de água no solo na saturação $\left(\mathrm{m}^{3} \mathrm{~m}^{-3}\right) ; \theta_{\mathrm{r}}$ o conteúdo residual de água no solo $\left(\mathrm{m}^{3} \mathrm{~m}^{-3}\right) ; \alpha$ representa o inverso da pressão de borbulhamento $\left(\mathrm{m}^{-1}\right)$ a partir da qual a água começa a ser drenada do solo previamente saturado; e n e m os parâmetros de ajuste da equação. 
O parâmetro $\theta_{\mathrm{s}}$ foi obtido por pesagem direta das amostras, após o processo de saturação. Os parâmetros $\theta_{\mathrm{r}}, \alpha$ e $\mathrm{n}$ foram obtidos por meio da rotina Solver da planilha eletrônica Excel.

A condutividade hidráulica do solo não saturado, $\mathrm{K}(\theta)$, foi obtida por meio da equação de Brooks \& Corey (1964):

$$
\mathrm{K}(\theta)=\mathrm{K}_{\mathrm{S}}\left(\frac{\theta-\theta_{\mathrm{r}}}{\theta_{\mathrm{S}}-\theta_{\mathrm{r}}}\right)^{\eta}
$$

sendo $\mathrm{K}_{\mathrm{s}}\left(\mathrm{mm} \mathrm{d}^{-1}\right)$ a condutividade hidráulica saturada do solo.

Para estimar a condutividade hidráulica saturada do solo $\left(\mathrm{K}_{\mathrm{s}}\right)$, foram realizados ensaios de infiltração com infiltrômetro de anel simples com $15 \mathrm{~cm}$ de diâmetro nas profundidades de 0,20 e 0,40 m, utilizando-se o método proposto por Haverkamp et al. (1994). Esse método consiste em anotar o tempo em que volumes constantes de água levam para infiltrarem no solo; esse volume de água pode variar de 70 a $250 \mathrm{~mL}$, dependendo da taxa de infiltração, a fim de evitar uma carga hidráulica e consequente fluxo forçado no solo. A infiltração acumulada é obtida calculando-se a razão entre o volume acumulado e a área do infiltrômetro de anel $\left(\mathrm{A}=176,71 \mathrm{~cm}^{2}\right)$.

Haverkamp et al. (1994) estabeleceram uma equação de infiltração para infiltrômetros a discos e infiltrômetros de anel simples válida para tempos curtos e médios:

$$
\mathrm{I}_{3 \mathrm{D}}=\mathrm{S} \sqrt{\mathrm{t}}+\left[\frac{2-\beta}{3} \cdot \mathrm{K}_{\mathrm{s}}+\frac{\gamma \mathrm{S}^{2}}{\mathrm{r} \Delta \theta}\right] \cdot \mathrm{t}
$$

(A)

(B)

(C)

sendo $\beta$ uma constante que se encontra entre $0<\beta<$ 1. Os diferentes termos da equação 10 são definidos como: (A) é a parte do volume infiltrado por capilaridade; (B), a parte do volume infiltrado por gravidade; e (C), a parte do volume infiltrado por capilaridade lateral (ligada à geometria axissimétrica tridimensional da infiltração). O primeiro termo da equação 10 é a sorvidade $\mathrm{S}\left(\mathrm{mm} \mathrm{d}^{-1 / 2}\right)$ e $\mathrm{K}_{\mathrm{s}}$ é a condutividade hidráulica saturada $\left(\mathrm{mm} \mathrm{d}^{-1}\right)$. O parâmetro $\mathrm{S}$ traduz a capacidade do solo em absorver água por capilaridade e depende essencialmente de $\Delta \theta$, ou seja, da variação do teor volumétrico de água entre o início e o final da infiltração.

Vandervaere et al. (2000) apresentaram que o regime transiente da infiltração axissimétrica a partir de um infiltrômetro a disco é adequadamente descrita por uma equação de dois termos, similar a de Philip (1957) para uma infiltração monodimensional. Dessa forma, pode-se escrever a equação 10 como:

com

$$
\mathrm{I}=\mathrm{C}_{1} \sqrt{\mathrm{t}}+\mathrm{C}_{2} \mathrm{t}
$$

$$
\mathrm{C}_{2}=\frac{2-\beta}{3} \cdot \mathrm{K}_{\mathrm{s}}+\frac{\gamma \mathrm{S}^{2}}{\mathrm{r} \Delta \theta}
$$

Os valores dos parâmetros das equações de van Genuchten (1980) para a curva de retenção (Equação 7) e de Brooks \& Corey (1964) para a curva de condutividade hidráulica (Equação 9) estão descritos no quadro 1.

A determinação do perfil do sistema radicular do capim Brachiaria decumbens foi realizado no período de abril a novembro de 2011. Foram abertas oito trincheiras (uma para cada mês) em locais diferentes e escolhidos aleatoriamente. As trincheiras tinham as seguintes dimensões: $0,90 \times 0,60 \times 0,80 \mathrm{~m}$ de comprimento, largura e profundidade, respectivamente, onde foi analisado o perfil com $0,50 \mathrm{~m}$ de profundidade por $0,50 \mathrm{~m}$ de largura, em camadas a cada $0,10 \mathrm{~m}$ de espessura, sendo espaçado da seguinte forma: 0,0-0,10; 0,10-0,20; 0,20-0,30; 0,30-0,40; e 0,40-0,50 m. Foram retirados monólitos com as seguintes dimensões 0,10 $\times 0,10 \times 0,10 \mathrm{~m}$, sendo cinco para cada camada, num total de 25 monólitos.

Os monólitos foram acondicionados em sacos plásticos e transportados ao Laboratório de Solos da UAG/UFRPE para separação do solo e das raízes. A separação foi feita por lavagem com água sobre uma peneira de 0,053 $\mathrm{mm}$ para evitar perdas das raízes. Depois de separadas do solo, as raízes foram acondicionadas em embalagens de alumínio e colocadas para secar em temperatura ambiente. Após a secagem, essas foram pesadas em balança analítica de precisão $(0,0001 \mathrm{~g})$. A massa das raízes contidas nos cinco monólitos de cada camada do perfil do solo foi somada, ou seja, cada camada formou um único valor. O sistema radicular do capim Brachiaria decumbens Stapf foi avaliado e apresentado pela massa das raízes em cada camada de solo, assim formando e caracterizando o perfil do sistema radicular.

A evapotranspiração de referência (ETo) foi obtida pelo método de Penmam-Monteith, padrão FAO, de acordo com Allen et al. (1998). Os dados necessários (temperatura e umidade relativa do ar, radiação solar e velocidade do vento) foram obtidos de uma estação meteorológica automática (Campbell Scientific Inc., USA), instalada no centro da área.

\section{RESULTADOS E DISCUSSÃO}

Observou-se (Quadro 2) que o solo estudado (Neossolo Regolítico), como esperado, apresenta elevados teores de areia (764,1 a 876,5 $\left.\mathrm{g} \mathrm{kg}^{-1}\right)$ e baixos teores de argila (35,3 a 73,8 $\left.\mathrm{g} \mathrm{kg}^{-1}\right)$. De acordo com Oliveira (2008), os Neossolos Regolíticos, especialmente na Região Nordeste, têm como característica geral o predomínio da fração areia. Segundo Santos et al. (2012), o predomínio de areia nesses solos está relacionado ao material de origem (quartzo). Em 
Quadro 1. Valores dos parâmetros das curvas de retenção da água no solo $\psi_{\mathrm{m}}(\theta)$ e da condutividade hidráulica $[K(\theta)]$ nas profundidades 0,20 e $0,40 \mathrm{~m}$

\begin{tabular}{|c|c|c|c|c|c|c|c|}
\hline Profundidade & $\mathbf{n}$ & $\mathbf{m}$ & $\eta$ & $\theta_{\mathrm{r}}$ & $\boldsymbol{\theta}_{\mathrm{s}}$ & $\alpha$ & $\mathbf{K}_{\mathrm{s}}$ \\
\hline $\mathrm{m}$ & & & & 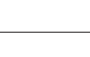 & 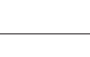 & $\mathrm{m}^{-1}$ & $\mathrm{~mm} \mathrm{~d}^{-1}$ \\
\hline 0,20 & 2,292 & 0,127 & 9,970 & 0,063 & 0,299 & 0,012 & 984,10 \\
\hline 0,40 & 2,264 & 0,118 & 10,626 & 0,046 & 0,326 & 0,110 & 682,56 \\
\hline
\end{tabular}

Quadro 2. Análise granulométrica, densidade do solo (Ds), densidade de partículas (Dp) e porosidade total (PT) do Neossolo Regolítico

\begin{tabular}{|c|c|c|c|c|c|c|}
\hline Camada & Areia & Silte & Argila & Ds & Dp & PT \\
\hline $\mathrm{m}$ & 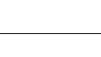 & $\mathrm{g} \mathrm{kg}^{-1}$ & 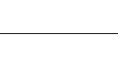 & 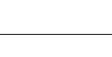 & & $\mathrm{m}^{3} \mathrm{~m}^{-3}$ \\
\hline $0,0-0,20$ & 876,5 & 88,2 & 35,3 & $1.520 \mathrm{a}$ & $2.720 \mathrm{a}$ & $0,441 \mathrm{~b}$ \\
\hline $0,20-0,40$ & 816,5 & 120,2 & 63,3 & $1.410 \mathrm{~b}$ & $2.700 \mathrm{a}$ & $0,478 \mathrm{a}$ \\
\hline $0,40-0,60$ & 764,1 & 162,1 & 73,8 & $1.410 \mathrm{~b}$ & $2.680 \mathrm{a}$ & $0,474 \mathrm{a}$ \\
\hline
\end{tabular}

Valores seguidos da mesma letra na coluna não diferem entre si pelo teste de Tukey a $5 \%$.

relação à densidade de partículas (Dp), notou-se que os valores tiveram pouca variação, de 2.680 a 2.720 $\mathrm{kg} \mathrm{m}^{-3}$, o que está dentro do intervalo encontrado para outros Neossolos Regolíticos (Santos et al., 2012). A densidade do solo (Ds) apresentou pouca variação; no entanto, foi maior na camada mais superficial $(0,0$ $0,20 \mathrm{~m}$ ), provavelmente em razão do maior efeito do pisoteio animal nessa camada. Esse maior valor de Ds nessa camada resultou numa menor porosidade total (PT). No entanto, de acordo com Corsini \& Ferraudo (1999), esse valor de Ds está abaixo do índice crítico do crescimento radicular de solos arenosos, que é $1.750 \mathrm{~kg} \mathrm{~m}^{-3}$.

A variação diária da precipitação pluvial e da umidade volumétrica nas camadas de 0,0-0,10;0,100,20; 0,20-0,30; e 0,30-0,40 m durante o período de $1 \% 3$ a 30/11/2011 é apresentada na figura 2 .

A precipitação pluvial atingiu seu maior valor (28,3 $\mathrm{mm}$ ) no dia 31/07/2011, o que representou quase $7 \%$ do valor total do período. No período do experimento, ocorreram mais três dias que se destacam com valores de precipitação pluvial acima de $10 \mathrm{~mm}$ : 03/05/2011, com 19,4 mm; 05/05/2011, com 13,8 m; e 24/05/201, com 23,5 mm. O valor total de precipitação no período analisado (março a novembro de 2011) foi de $427,7 \mathrm{~mm}$, o qual corresponde a $67 \%$ do valor histórico (585,6 mm) para o mesmo período (Figura 1).

Em relação à umidade volumétrica do solo, observou-se que os valores acompanham os eventos de precipitação, aumentando ou diminuindo os valores de umidade em razão da presença ou ausência de precipitação. Pode-se notar, ainda na figura 2, nos períodos de 31/07/2011 a 23/08/2011 e 13/11/2011 a $30 / 11 / 2011$, que em todas as camadas avaliadas ocorreu decréscimo na umidade volumétrica do solo, causado pela ausência ou pouca precipitação pluvial, verificando-se que as camadas mais superficiais do solo (0,0-0,10 e 0,10-0,20 m) apresentaram maiores oscilações nos valores da umidade volumétrica, ocorrendo o inverso nas camadas mais profundas $(0,20$ 0,30 e 0,30-0,40 m).

A atuação conjunta dos componentes atmosféricos e do sistema radicular da pastagem, concentrando nas camadas mais superficiais do solo, é responsável pela retirada de água dele, assim explicando a maior variação dos valores de umidade volumétrica nas camadas mais superficiais, principalmente na camada de 0,0-0,10 m. Entretanto, nessas camadas a recarga hídrica acontece também de forma mais efetiva. Cruz et al. (2005) verificaram que na estação mais chuvosa as camadas mais superficiais do solo contribuíram com mais de $70 \%$ da água evapotranspirada.

A maior Ds observada na camada mais superficial (0,0-0,20 m) (Quadro 2) pode ajudar a explicar o fato de as camadas mais superficiais do solo apresentarem menores valores de umidade volumétrica, quando comparadas às mais profundas.

O aumento da densidade pode propiciar ao solo diminuição da porosidade total por causa da redução dos espaços vazios e alteração na distribuição dos tamanhos dos poros, que por sua vez influencia diretamente para a diminuição do teor de umidade volumétrica, bem como no comportamento das propriedades hidráulicas do solo (Imhoff et al., 2000).

Apresenta-se, na figura 3, a evolução da massa seca relativa (massa de cada camada dividida pela massa total) do sistema radicular do capim Brachiaria decumbens Stapf, ao longo dos períodos de coleta.

Independentemente do período de coleta (abril a novembro de 2011), a maior parte do sistema radicular da pastagem concentrou-se entre as camadas de 0,00,10 e 0,10-0,20 m. Observou-se que o perfil do sistema radicular seguiu a mesma evolução para todos os 


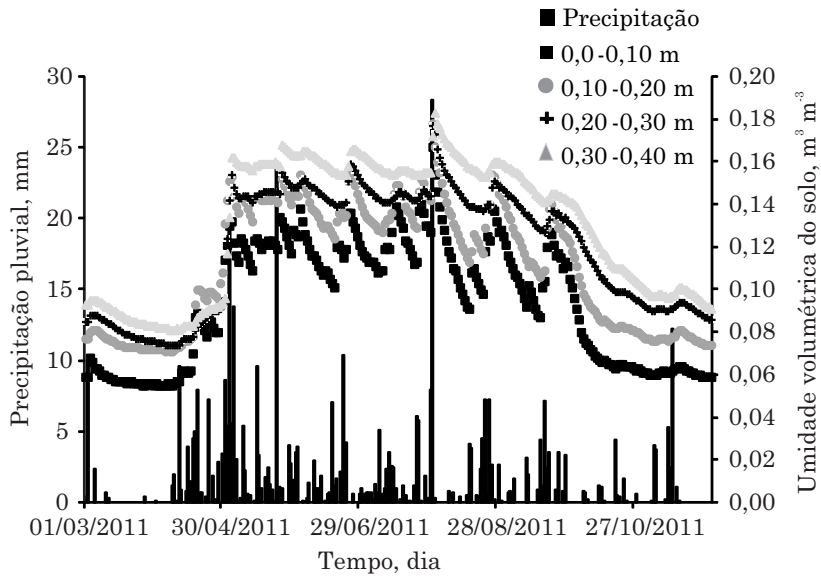

Figura 2. Evolução da umidade volumétrica do solo e da precipitação pluvial de $1^{\circ}$ de março a 30 de novembro de 2011.

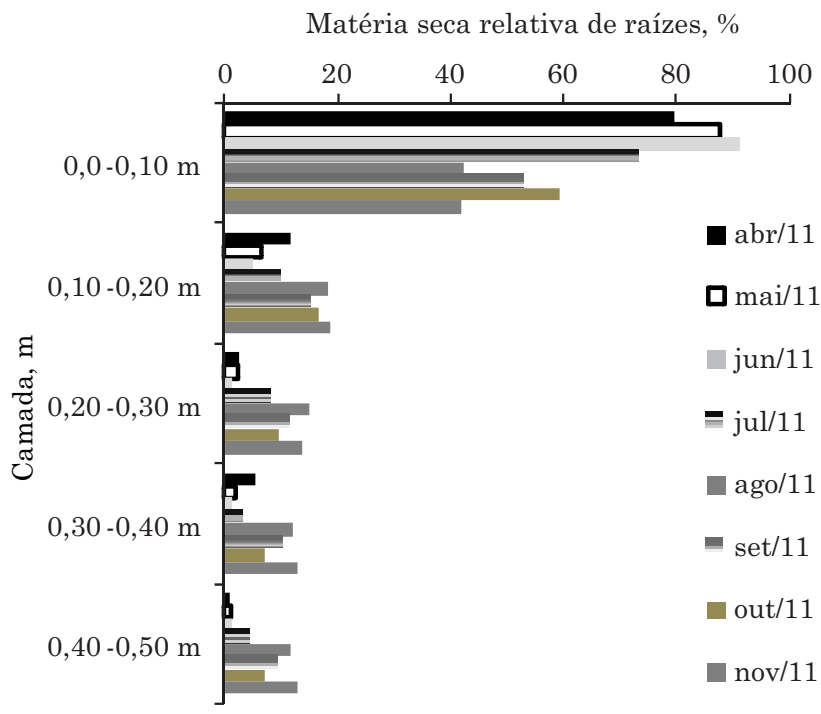

Figura 3. Evolução do perfil do sistema radicular do capim Brachiária decumbens Stapf de abril a novembro de 2011.

períodos analisados. O maior percentual encontrado $(91,4 \%)$ foi na camada de $0,0-0,10 \mathrm{~m}$ no mês de junho, seguido do mês de maio, com $87,7 \%$. No entanto, os valores mais baixos foram observados nas camadas mais profundas, sendo os meses de abril, maio e junho o que obtiveram os valores mais baixos, em torno de 1 \%. Corrêa et al. (1999), avaliando a distribuição espacial de raízes de capim-tanzânia (Panicum maximum cv. Tanzânia), também encontraram maiores percentuais (cerca de $88 \%$ ) de raízes nas camadas mais superficiais (camadas de 0,0-0,10 e 0,10-0,20 m).

O início das chuvas estimulou o crescimento das raízes do capim-braquiária. Pode-se observar na figura 3 que a partir do mês de abril houve incremento positivo das raízes para todas as camadas estudadas, mas a camada de $0,0-0,10 \mathrm{~m}$ foi a que teve a maior evolução.

Entretanto, os dados citados anteriormente evidenciaram variabilidade na profundidade efetiva do sistema radicular. Segundo Bernardo et al. (2005), a profundidade efetiva do sistema radicular deve ser tal que, pelo menos $80 \%$ das raízes da cultura esteja nela contida. Essa variabilidade foi dividida em três períodos, o primeiro foi de abril a junho com a profundidade efetiva do sistema radicular compreendida na camada de 0,0-0,10 m; o segundo, no mês de julho, em que a profundidade aumentou e passou a ser na camada de 0,0-0,20 m; e por fim, de agosto a novembro, em que a profundidade efetiva do sistema radicular passou a ser na camada de 0,0 $0,30 \mathrm{~m}$.

Esses dados indicam que com a diminuição das chuvas, e consequentemente da umidade do solo, no período de agosto a novembro (Figura 2), ocorreu aumento da concentração de raízes nas camadas mais profundas (Figura 3). Nesse sentido, Cunha et al. (2007), estudando o comportamento do sistema radicular do capim- tanzânia submetido a diferentes níveis de irrigação e turno de rega, relataram que a maior profundidade efetiva do sistema radicular foi encontrada no tratamento em que o capim foi submetido a uma menor lâmina e menor turno de rega.

De acordo com Shao et al. (2008), com a diminuição da umidade do solo ocorrem alterações na distribuição e atividade do sistema radicular, oscilando assim a disponibilidade de água para as plantas de acordo com as habilidades dessas em expandir ou aprofundar o sistema radicular, para explorar um volume maior de solo.

A evolução dos componentes do balanço hídrico em Brachiaria decumbens Stapf é apresentada no quadro 3. A camada de solo em que foi realizado o balanço hídrico foi de 0-0,30 $\mathrm{m}$, que correspondeu à profundidade efetiva do sistema radicular (Figura 3).

Observa-se que a variação do armazenamento de água no solo $(\Delta \mathrm{A})$ acompanhou as variações da precipitação pluvial, sendo seu valor total em todo período analisado de $-0,4 \mathrm{~mm}$. A $\Delta \mathrm{A}$ apresentou uma oscilação de -18,9 a +18,0 mm, o que evidencia que em determinados períodos ocorreu perda de água, isto é, as perdas por drenagem (-Q) e seu consumo pela cultura mais a evaporação da água diretamente da superfície do solo (ET) foi superior à quantidade fornecida pela precipitação $(\mathrm{P})$, e em outros períodos ocorreu ganho de água. A $\Delta \mathrm{A}$ corresponde ao saldo de água no solo, se no intervalo de tempo considerado (nesta pesquisa cada subperíodo teve 15 ou 16 dias); se as entradas (precipitação) de água no volume de solo forem maiores que as saídas (evapotranspiração e drenagem) a $\Delta \mathrm{A}$ será positiva (isto ocorreu em 10 subperíodos), caso contrário será negativa (isto ocorreu em oito subperíodos). 
Quadro 3. Componentes do balanço hídrico em Brachiaria decumbens de $1^{\circ}$ de março a 30 de novembro de 2011

\begin{tabular}{|c|c|c|c|c|c|}
\hline Subperíodo & Dia & $\Delta \mathbf{A}$ & $\mathbf{P}$ & $\mathbf{Q}$ & ET \\
\hline $1-1^{\circ} / 03 / 2011$ a $15 / 03 / 2011$ & 15 & $-1,3$ & 13,7 & $-0,25$ & 14,75 \\
\hline $2-16 / 03 / 2011$ a $31 / 03 / 2011$ & 16 & $-1,5$ & 0,4 & $-0,16$ & 1,74 \\
\hline $3-1^{\circ} / 04 / 2011$ a $15 / 04 / 2011$ & 15 & 1,1 & 18,6 & $-0,14$ & 17,36 \\
\hline $4-16 / 04 / 2011$ a $30 / 04 / 2011$ & 15 & 9,3 & 36,2 & $-0,68$ & 26,22 \\
\hline $5-1^{\circ} / 05 / 2011$ a $15 / 05 / 2011$ & 15 & 18,0 & 74,6 & $-10,69$ & 45,91 \\
\hline $6-16 / 05 / 2011$ a $31 / 05 / 2011$ & 16 & 1,3 & 44,7 & $-12,99$ & 30,41 \\
\hline $7-1^{\circ} / 06 / 2011$ a $15 / 06 / 2011$ & 15 & $-4,5$ & 16,7 & $-10,26$ & 10,94 \\
\hline $8-16 / 06 / 2011$ a $30 / 06 / 2011$ & 15 & 3,2 & 29,5 & $-12,30$ & 14,00 \\
\hline $9-1^{\circ} / 07 / 2011$ a $15 / 07 / 2011$ & 15 & 1,7 & 23,3 & $-7,78$ & 13,82 \\
\hline $10-16 / 07 / 2011$ a $31 / 07 / 2011$ & 16 & 10,0 & 53,7 & $-17,39$ & 26,31 \\
\hline $11-1^{\%} / 08 / 2011$ a $15 / 08 / 2011$ & 15 & $-18,2$ & 2,7 & $-12,44$ & 8,46 \\
\hline $12-16 / 08 / 2011$ a $31 / 08 / 2011$ & 16 & 6,8 & 36,0 & $-8,43$ & 20,77 \\
\hline $13-1^{\circ} / 09 / 2011$ a $15 / 09 / 2011$ & 15 & $-10,4$ & 9,6 & $-3,74$ & 16,26 \\
\hline $14-16 / 09 / 2011$ a $30 / 09 / 2011$ & 15 & 2,1 & 27,1 & $-5,28$ & 19,72 \\
\hline $15-1^{\%} / 10 / 2011$ a $15 / 10 / 2011$ & 15 & $-12,0$ & 4,1 & $-0,13$ & 15,97 \\
\hline $16-16 / 10 / 2011$ a $31 / 10 / 2011$ & 16 & $-3,7$ & 7,7 & $-0,07$ & 11,33 \\
\hline $17-1^{\%} / 11 / 2011$ a $15 / 11 / 2011$ & 15 & 0,3 & 29 & $-0,20$ & 28,50 \\
\hline $18-16 / 11 / 2011-30 / 11 / 2011$ & 15 & $-2,6$ & 0,1 & $-0,22$ & 2,48 \\
\hline Total & 275 & $-0,40$ & 427,70 & $-103,14$ & 324,96 \\
\hline
\end{tabular}

$\Delta \mathrm{A}$, variação do armazenamento de água no solo; $\mathrm{P}$, precipitação pluvial; $\mathrm{Q}$, fluxo de água no solo (valores negativos indicam drenagem e positivos, ascensão capilar); e ET, evapotranspiração.

Para os valores do fluxo de água no limite inferior do volume de solo $(\mathrm{Q})$, observou-se que ocorreu somente drenagem (valores negativos) e que esse também seguiu as variações da precipitação pluvial, com maior drenagem nos períodos de maior precipitação. O maior evento de drenagem ocorreu no subperíodo 10 (16/ 07/2011 a 31/07/2011) com -17,4 mm; o valor total de drenagem no período experimental foi de -103,14 $\mathrm{mm}$, o que representa $24,12 \%$ de toda a água fornecida via precipitação pluvial. Esse elevado valor de drenagem sugere que sejam tomadas medidas, por parte dos produtores, para diminuir essa perda de água para as camadas mais profundas, como a adoção de práticas de manejo que aumentem a retenção de água pelo solo.

Brito et al. (2009) realizaram o balanço hídrico num Latossolo Vermelho e num Latossolo VermelhoAmarelo em Jaboticabal e Pirassununga e encontraram que as perdas de água por drenagem foram -191,7 mm e -111,1 mm, respectivamente. De acordo com esses autores, nos períodos de alta pluviosidade, a drenagem foi significativa, alertando para possíveis problemas no manejo em relação a uma potencial contaminação do lençol freático.

Apesar de o capim-braquiária necessitar de grande demanda hídrica, em torno de $1.200 \mathrm{~mm}$, ele não suporta o alagamento e assim necessita que o solo tenha boa drenagem. Quando o capim-braquiária é submetido a um estresse hídrico, pelo alagamento do solo, acontece a senescência de lâminas foliares (Mattos et al., 2005). Em relação a esse fato, constatou-se que o tipo de solo da área experimental (Neossolo Regolítico) dá bom suporte ao capim-braquiária, pois apresenta boa drenagem, não tendo excesso de água, que pode prejudicar no desenvolvimento da cultura. De acordo com Dias Filho \& Carvalho (2000), o alagamento do solo, em razão da má drenagem, pode reduzir em $52 \%$ a fotossíntese de Brachiaria decumbens. Entretanto, esses solos apresentam-se com baixa capacidade de retenção de umidade (Borchartt et al., 2011), fato que explica os teores de umidade volumétrica encontrados no período experimental.

Em relação à evapotranspiração (ET), observou-se que os maiores valores de ET aconteceram nos subperíodos de maiores eventos de precipitação pluvial. Observa-se no quadro 3 que a ET teve um valor total de $324,96 \mathrm{~mm}$ e médio de $1,2 \mathrm{~mm} \mathrm{~d}^{-1}$, em que 0 subperíodo 5 (1\%05/2011 a 15/05/2011) com 45,91 mm obteve o maior valor; entretanto, o menor valor de ET foi observado no subperíodo 2 (16/03/2011 a 31/03/ 2011), com 1,74 mm. Essa diferença de valores de ET pode ser explicada pelo fato de que no subperíodo 5 ocorreu o maior valor de precipitação pluvial (74,6 $\mathrm{mm}$ ), enquanto no subperíodo 2 só ocorreram $0,4 \mathrm{~mm}$ de precipitação.

Brito et al. (2009), em estudos de balanço hídrico com cana-de-açúcar em Jaboticabal e Pirassununga, $\mathrm{SP}$, também encontraram que a ET seguiu a 
distribuição temporal do conteúdo de água no solo, decorrente principalmente da distribuição das chuvas.

O valor médio diário da ET encontrado nesta pesquisa está abaixo de outros encontrados na literatura; por exemplo, Meireles et al. (2011) encontraram ET de $2,6 \mathrm{~mm} \mathrm{~d}^{-1}$ para a Brachiaria brizantha na região do Cerrado. A diferença entre o valor de ET deste estudo e desses autores pode ser em razão das diferentes condições edafoclimáticas, além do método utilizado, uma vez que na pesquisa de Meirelles et al. (2011) foi usado o método do balanço de energia - correlação dos turbilhões e, neste estudo, o do balanço hídrico no solo.

Na figura 4, evidenciam-se os valores médios diários da precipitação pluvial (P), da evapotranspiração (ET), da evapotranspiração de referência (ETo), além dos valores da relação ET/ETo, durante os 18 subperíodos avaliados, que compreende ao período de 1\%03/2011 a 30/11/2011.

Verificou-se que existe uma relação direta entre precipitação pluvial (P) e evapotranspiração diária (ET), com os maiores valores de ET ocorrendo nos períodos de maior disponibilidade hídrica; por exemplo, no subperíodo 5, a ET foi de 3,06 $\mathrm{mm} \mathrm{d}^{-1}$ e a precipitação foi de $4,97 \mathrm{~mm} \mathrm{~d}^{-1}$. Em relação à ETo, notou-se que os valores mais baixos (inferiores a $3,0 \mathrm{~mm} \mathrm{~d}^{-1}$ ) ocorreram dos subperíodos 5 a 12 , que corresponde aos meses de maio a agosto; e os maiores valores (acima de 3,0 $\mathrm{mm} \mathrm{d}^{-1}$ ) ocorreram nos subperíodos de 1 a 4 (meses de março a abril) e de 13 a 18 (meses de setembro a novembro). De acordo com Borges Júnior et al. (2012), que estimaram a ETo para a microrregião de Garanhuns, o semestre primavera-verão (meses de setembro a março) é caracterizado por uma demanda atmosférica mais elevada (ETo em torno de $4,5 \mathrm{~mm} \mathrm{~d}^{-1}$ ), em relação ao semestre outono-inverno (ETo em torno de $3,0 \mathrm{~mm} \mathrm{~d}^{-1}$ ).

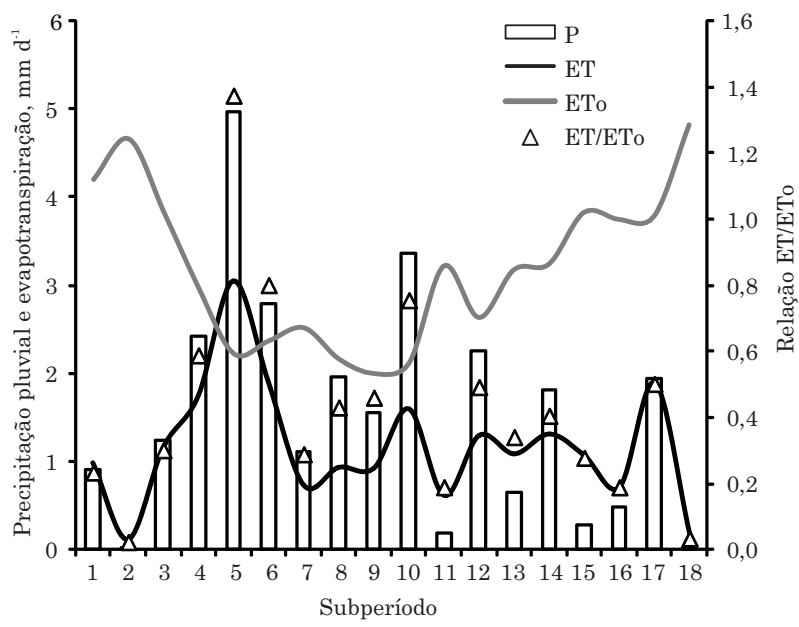

Figura 4. Evapotranspiração (ET), evapotranspiração de referência (ETo), precipitação pluvial (P) e razão ET/ETo, durante os diferentes subperíodos (1\%03/2011 a 30/11/2011).
Em relação aos valores da razão ET/ETo, observouse que essa sempre foi abaixo de 1 , à exceção do subperíodo 5, que foi de 1,37. A relação ET/ETo média para todo período foi de 0,37 . De acordo com Fontana et al. (1991), a relação entre ET e ETo pode indicar se a cultura está sofrendo estresse hídrico, uma vez que essa relação expressa o consumo relativo de água. A razão ET/ETo inclui, além da disponibilidade de água no solo, também a demanda evaporativa da atmosfera (ETo). Desse modo, observou-se que em quase todo período analisado o capim-braquiária sofreu estresse hídrico, pois a relação ET/ETo ficou bem abaixo de 1 .

Esses dados indicam a necessidade de os produtores realizarem irrigação, para que possam aumentar os níveis de água no solo e garantir maiores níveis de evapotranspiração, o que é agronomicamente desejável (Prevedello et al., 2007). No entanto, em razão dos altos níveis de drenagem observados (Quadro 3), fazse necessário que essa irrigação seja mais frequente (menor turno de rega) e com menores lâminas de água, além de práticas de manejo que aumentem a retenção de água pelo solo.

\section{CONCLUSÕES}

1. Os períodos com elevadas pluviosidades resultaram num maior armazenamento de água no solo, em maiores valores de drenagem e de evapotranspiração.

2. O fluxo de água no limite inferior $(\mathrm{z}=0,30 \mathrm{~m})$ do solo ocorreu somente no sentido descendente, sendo perdidos 103,14 mm de água por drenagem, o que representa $24,12 \%$ de toda a água fornecida à cultura.

3. A evapotranspiração acumulada da Brachiaria decumbens Stapf foi de $324,96 \mathrm{~mm}$, com valor médio de $1,2 \mathrm{~mm} \mathrm{~d}^{-1}$.

4. A cultura sofreu estresse hídrico, em quase todo período experimental, tendo em vista os valores da relação ET/ETo serem bem abaixo de 1.

5. Os baixos valores da razão ET/ETo indicaram a necessidade de se realizar irrigação para se diminuir o déficit hídrico. No entanto, por causa dos elevados valores de drenagem, recomendam-se irrigações frequentes e com menores lâminas, além de práticas de manejo que aumentem a retenção de água pelo solo.

\section{AGRADECIMENTOS}

Os autores agradecem ao Conselho Nacional de Desenvolvimento Científico e Tecnológico (CNPq) pelos recursos disponíveis, por meio do Projeto: "Balanço hídrico e de energia em pastagens na microrregião de Garanhuns (processo 475094/2009-3)"; À Fundação de 
Amparo à Ciência e Tecnologia do Estado de Pernambuco (FACEPE) pela bolsa de mestrado ao primeiro autor e pela concessão de recursos financeiros por meio dos projetos "Impacto de mudanças climáticas sobre a cobertura e uso da terra em Pernambuco: geração e disponibilização de informações para o subsídio a políticas públicas" (Edital FACEPE 02/2009 - Mudança Climática Global) e "Dinâmica da Água e de Carbono em Ecossistemas no Estado de Pernambuco" (Edital FACEPE 12/2010 PRONEM/ FACEPE/CNPq); À FINEP pelos recursos financeiros por meio do projeto "Estudos hidrológicos e sedimentológicos em Bacias experimentais e representativas do semiárido e cerrado" (Edital MCT/ FINEP CT-HIDRO 01/2010) e ao Professor Antonio de Pádua Montenegro, pela disponibilização da área experimental.

\section{LITERATURA CITADA}

ALLEN, R.G.; PEREIRA, L.S.; RAES, D. \& SMITH, M. Crop evapotranspiration - Guidelines for computing crop water requirements. Roma, FAO, 1998. 300p. (Irrigation and Drainage Paper, 56)

ANDRADE, M.C.O. Pernambuco e o trópico. R. Inst. Est. Bras., 45:11-20, 2007.

AGÊNCIA PERNAMBUCANA DE ÁGUAS E CLIMA . APAC. Disponível em: <http://www.apac.pe.gov.br>. Acesso em: 05 jul. 2013.

BARBOSA, R.A. Morte de pastos de braquiárias. Campo Grande, Embrapa Gado de Corte, 2006. 206p.

BERNARDO, S.; SOARES, A.A. \& MANTOVANI, E.C. Manual de irrigação. 7.ed. Viçosa, MG, Imprensa Universitária, 2005. 611p.

BORCHARTT, L.; SILVA, I.F.; SANTANA, E.O.; SOUZA, C. \& FERREIRA, L.E. Adubação orgânica da batata com esterco bovino no município de Esperança - PB. R. Ci. Agron., 42:482-487, 2011.

BORGES JÚNIOR, J.C.F.; ANJOS, R.T.; SILVA, T.J.A.; LIMA, J.R.S. \& ANDRADE, C.L.T. Métodos de estimativa da evapotranspiração de referência diária para a microrregião de Garanhuns, PE. R. Bras. Eng. Agríc. Amb., 16:380-390, 2012.

BRITO, A.S.; LIBARDI, P.L. \& GHIBERTO, P.J. Componentes do balanço de água no solo com cana-deaçúcar, com e sem adubação nitrogenada. R. Bras. Ci. Solo, 33:295-303, 2009.

BROOKS, R.H. \& COREY, A.T. Hydraulic properties of porous media. Fort Collins, Colorado State University, 1964. (Hydrology Paper, 3)

BURDINE, N.T. Relative permeability calculation from size distribution data. Trans. AIME, 198:71-78, 1953.
CORRÊA, L.A.; KANO, T.; MACEDO, M.C.M.; EUCLIDES, V.P.B., BERETTA, L.G.R.; SANTOS JR., J.D.G. \& BONO, J.A.M. Produção de raízes em cinco forrageiras tropicais sob pastejo na região dos cerrados. In: REUNIÃO ANUAL DA SOCIEDADE BRASILEIRA DE ZOOTECNIA. 36., Porto Alegre, 1999. Anais... Porto Alegre, 1999. CD-ROM

CORSINI, P.C. \& FERRAUDO, A.S. Efeitos de sistemas de cultivo na densidade e macroporosidade do solo e no desenvolvimento radicular do milho em Latossolo Roxo. Pesq. Agropec. Bras., 34:289-298, 1999.

CRUZ, A.C.R.; LIBARDI, P.L.; CARVALHO, L.A. \& ROCHA, G.C. Balanço de água no volume de solo explorado pelo sistema radicular de uma planta de citros. R. Bras. Ci. Solo, 29:1-10, 2005.

CUNHA, F.F.; SOARES, A.A.; SEDIYAMA, G.C.; MANTOVANI, E.C.; PEREIRA, O.G.; ABREU, F.V.S. \& SOUZA, D.O. Avaliação do sistema radicular do capimtanzânia submetido a diferentes níveis de irrigação e turnos de rega. Eng. Agric., 15:200-211, 2007.

DIAS FILHO, M.B. \& CARVALHO, C.J. Physiological and morphological responses of Brachiaria spp. to flooding. Pesq. Agropec. Bras., 35:1959-1966, 2000.

EMPRESA BRASILEIRA DE PESQUISA AGROPECUÁRIA . EMBRAPA. Centro Nacional de Pesquisa de Solos. Manual de métodos de análise de solo. 2.ed. Rio de Janeiro, 1997. $212 \mathrm{p}$.

EUCLIDES, V.P.B.; FLORES, R.; MEDEIROS, R.N. \& OLIVEIRA, M.P. Diferimento de pastos de braquiária cultivares Basilisk e Marandu, na região do Cerrado. Pesq. Agropec. Bras., 42:273-280, 2007.

FONTANA, D.C.; BERLATO, M.A.; LAUSCHNER, M.H. \& MELLO, R.W. Modelo de estimativa de rendimento de soja no Estado do Rio Grande do Sul. Pesq. Agropec. Bras., 36:399-403, 2001.

HAVERKAMP, R.; ROSS, P.J.; SMETTEM, K.R.J. \& PARLANGE, J.Y. Three dimensional analysis of infiltration from the disc infiltrometer. 2. Physically based infiltration equation. Water Resour. Res., 30:2.931-2.935, 1994.

HILLEL, D. Environmental soil physics. New York, Academic Press, 1998. 771p.

INSTITUTO BRASILEIRO DE GEOGRAFIA E ESTATÍSTICA - IBGE. Censo Agropecuário 2006. Rio de Janeiro, 2006. $146 \mathrm{p}$.

IMHOFF, S.; SILVA, A.P. \& TORMENA, C.A. Aplicações da curva de resistência no controle da qualidade física de um solo sob pastagem. Pesq. Agropec. Bras., 35:1.493-1.500, 2000 .

LIBARDI, P.L. Dinâmica da água no solo. 2.ed. Piracicaba, ESALQ, 2000. 509p.

LIMA, J.R.S.; ANTONINO, A.C.D.; ANDRADE, A.P.; SOUZA, C.; SOARES, W.A.; SOUZA, E.S. \& SILVA, I.F. Comparação da sonda de nêutrons e de sensores tipo TDR para a determinação dos componentes do balanço hídrico no solo e evapotranspiração do feijão caupi. Agropec. Técn., 27:21-29, 2006b. 
LIMA, J.R.S.; ANTONINO, A.C.D.; SOARES, W.A.; SOUZA, E.S. \& LIRA, C.A.B.O. Balanço hídrico no solo cultivado com feijão caupi. R. Bras. Ci. Agron., 1:89-95, 2006a.

MATTOS, J.L.S.; GOMIDE, J.A. \& HUAMAN, C.A.M. Crescimento de espécies de Brachiaria sob déficit hídrico e alagamento a campo. R. Bras. Zootec., 34:755-764, 2005.

MEIRELLES, M.L.; FRANCO, A.C.; FARIAS, S.E.M. \& BRACHO, R. Evapotranspiration and plant-atmospheric coupling in a Brachiaria brizantha pasture in the Brazilian savannah region. Grass Forage Sci., 66:206-213, 2011.

NICOLOSO, R.S.; LOVATO, T.; AMADO, T.J.C.; BAYER, C. \& LANZANOVA, M.E. Balanço do carbono orgânico no solo sob integração lavoura-pecuária no sul do Brasil. R. Bras. Ci. Solo, 32:2425-2433, 2008.

OLIVEIRA, J.B. Pedologia aplicada. 3.ed. Piracicaba, FEALQ, 2008. 592p.

PHILIP, J.R. The Theory of infiltration: 4.Sorptivity and algebraic infiltration equations. Soil Sci., 84:257-264, 1957.

PREVEDELLO, C.L.; MAGGIOTTO, S.R.; LOYOLA, J.M.T.; DIAS, N.L \& BEPPLER NETO, G. Balanço de água por aquisição automática de dados em cultura de trigo (Triticum aestivum L.). R. Bras. Ci. Solo, 31:1-8, 2007.
SANTOS, J.C.B.; SOUZA JÚNIOR, V.S.; CORREAA, M.M.; RIBEIRO, M.R.; ALMEIDA, M.C. \& BORGES, L.E.P. Caracterização de Neossolos Regolíticos da região semiárida do Estado de Pernambuco. R. Bras. Ci. Solo, 36:683-696, 2012.

SHAO, H.B.; CHU, L.; JALEEL, C.A. \& ZHAO, C. Waterdeficit stress-induced anatomical changes in higher plants. CR. Biol., 331:215-225, 2008.

van GENUCHTEN, M.T. A closed-form equation for predicting the hydraulic conductivity of unsatured soils. Soil Sci. Soc. Am. J., 44:892-898, 1980.

VANDERVAERE, J.P.; VAUCLIN M. \& ELRICK, D.E. Transient flow from tension infiltrometers: I. The twoparameter equation. Soil Sci. Soc. Am. J., 64:1263-1272, 2000 .

WARD, P.R.; FLOWER, K.C.; CORDINGLEY, N.; WEEKS, C. \& MICIN S.F. Soil water balance with cover crops and conservation agriculture in a Mediterranean climate. Field Crop Res., 132:33-39, 2012.

YDOYAGA, D.F.; LIRA, M.A.; SANTOS, M.V.F.; DUBEUX JÚNIOR, J.C.B.; SILVA, M.C.; SANTOS, V.F. \& FERNANDES, A.P.M. Métodos de recuperação de pastagens de Brachiaria decumbens Stapf. no Agreste Pernambucano. R. Bras. Zootec., 35:699-705, 2006. 